\title{
Instrumentation for the NEESR Sand Aging Field Experiment
}

\author{
David A. Saftner ${ }^{1}$, S.M. ASCE, Russell A. Green ${ }^{2}$, P.E., M. ASCE, Roman D. Hryciw ${ }^{3}$, \\ M. ASCE, and Jerome P. Lynch ${ }^{4}$, A.M. ASCE \\ ${ }^{1}$ Graduate Student Research Assistant, Dept. of Civil and Environmental Engineering, University of \\ Michigan, Ann Arbor, MI 48109-2125; dsaftner@umich.edu \\ ${ }^{2}$ Associate Professor, Dept. of Civil and Environmental Engineering, University of Michigan, Ann \\ Arbor, MI 48109-2125; rugreen@umich.edu \\ ${ }^{3}$ Professor, Dept. of Civil and Environmental Engineering, University of Michigan, Ann Arbor, MI \\ 48109-2125; romanh@umich.edu \\ ${ }^{4}$ Assistant Professor, Dept. of Civil and Environmental Engineering, University of Michigan, Ann Arbor, \\ MI 48109-2125; jerlynch@umich.edu
}

\begin{abstract}
This paper describes the instrumentation being developed and/or used for monitoring the post-liquefaction time-dependent changes in the state and properties of sand. As part of the NEESR project "NEESR - II: Mechanisms and Implications of Time-Dependent Changes in the State and Properties of Recently Liquefied Sands," a field study is being performed which involves the inducement of liquefaction in a saturated sand deposit via explosives, a vibroflot, and a NEES vibroseis. Subsequent to liquefaction, the time-dependent changes, commonly referred to as "aging," in the state and properties of the liquefied sand will be monitored for months to years. Central to the field study is the measurement of accelerations, settlements, and pore water pressures during and subsequent to liquefaction. Monitoring these parameters will allow the authors to compare the various methods used to breakdown the soil structure with the magnitude of disturbance and subsequent aging.
\end{abstract}

\section{INTRODUCTION}

Presented herein is an overview of the instrumentation and data acquisition systems that are being used in an ongoing "sand aging" field study. Sand aging refers to the time-dependent strength gain that often occurs in recently deposited, densified, and/or liquefied granular soils. The most common manifestation of the aging phenomenon is an increase with time in standard penetration test (SPT) or cone penetration test (CPT) resistance and/or small strain shear wave velocity, $\mathrm{V}_{\mathrm{s}}$. Although several studies have hypothesized the mechanisms underlying the aging phenomenon, questions remain regarding all of them. The present study entails a well-instrumented field study (as well as a synergistic laboratory study) with the goal of providing more insight into the mechanisms underlying this intriguing phenomenon. 
The field portion of this study entails the rapid breakdown of the structure of saturated sand using three different methods: explosives, vibrocompaction, and vibroseis. Several case studies identified aging effects after explosive compaction of loose, saturated sand (Mitchell and Solymar, 1984; Charlie et al., 1992; Ashford et al., 2004), with blast gas dissipation being one hypothesized mechanism (Dowding and Hryciw, 1986). Additionally, aging effects are commonly observed following vibrocompaction (e.g., Schmertmann, 1987), with micro-level particle rearrangement being one hypothesized mechanism (Mesri et al., 1990) and the introduction of heavily aerated water in the sand during jetting of the vibroflot into the soil profile being another (Personal Communication with Dr. Wilhelm Degen, Vibro Systems, Inc.). Finally, a Network for Earthquake Engineering Simulation (NEES) vibroseis from the University of Texas at Austin will be used to liquefy the sand profile, where the vibroseis will neither introduce blast gases nor aerated water into the soil. By using these three methods to induce liquefaction in well instrumented, juxtaposed locations in the same sand profile, the authors can gain insights into the mechanisms underlying the aging phenomenon.

The instrumentation that will be employed in the field study includes accelerometers, pore pressure transducers, and settlement tubes. Both tethered and wireless data acquisition systems will be used to collect the data. The instruments will be installed in an array so that the various parameters can be measured as a function of distance from the energy source.

In this paper, the characteristics of the field test site are discussed first. Next, an overview of the instrumentation is presented, followed by a discussion of the data acquisition systems.

\section{SITE CHARACTERISTICS}

The authors characterized the field study site using vision cone penetration tests (VisCPT), Marchetti dilatometer tests (DMT), seismic cone penetration tests (SCPT), and grain size analysis. The site is an active sand quarry owned by Mulzer Crushed Stone, Inc. and is located in southwestern Indiana. The site profile consists of a clay cap of approximately $2 \mathrm{~m}$ overlying a thick deposit of sand. The water table at the time of the site investigation was approximately $1.75 \mathrm{~m}$ below the ground surface. Figure 1 shows representative CPT log from the site. As may be observed from this figure, there is a loose sand layer from 2.5 to $3.2 \mathrm{~m}$ below the ground surface. Immediately below the loose sand layer is a dense sand layer, which will allow the influence of density on the aging phenomenon to be discerned.

The Unified Soil Classification of the sand at the test site is "poorly graded sand" (SP), with a coefficient of uniformity of 2.05 and a coefficient of gradation of 0.78 . Figure 2 shows the grain size distribution curve for the sand. As may be observed from this figure, the grain size curve falls close to the "coarse boundary" that defines the "most liquefiable soil." The VisCPT recorded movement of sand (or boiling) as the CPT probe advanced through the loose sand layer, which clearly indicates that this soil is liquefiable. 


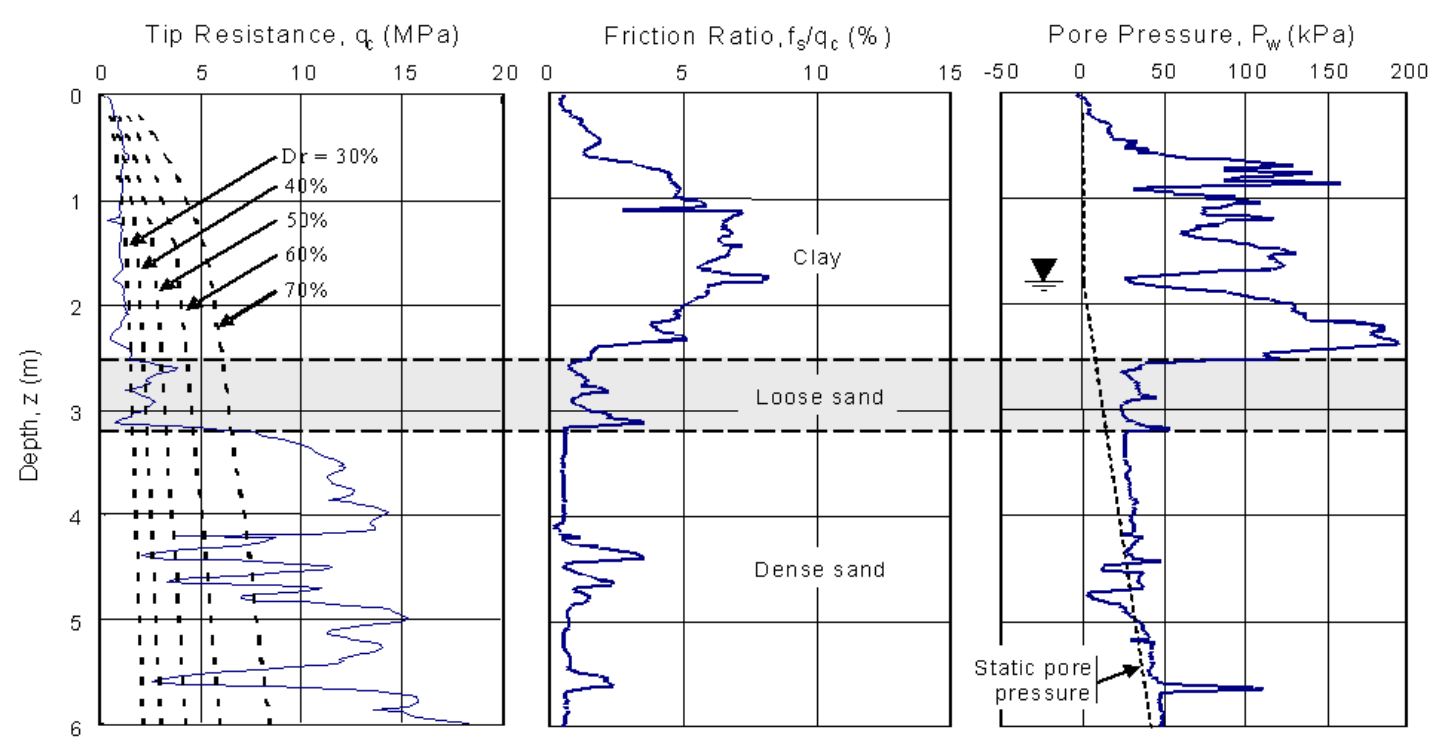

FIG. 1. CPT logs from the field test site. Superimposed on the tip resistance log are contours of equivalent relative density per Jamiolkowski et al. (1985).

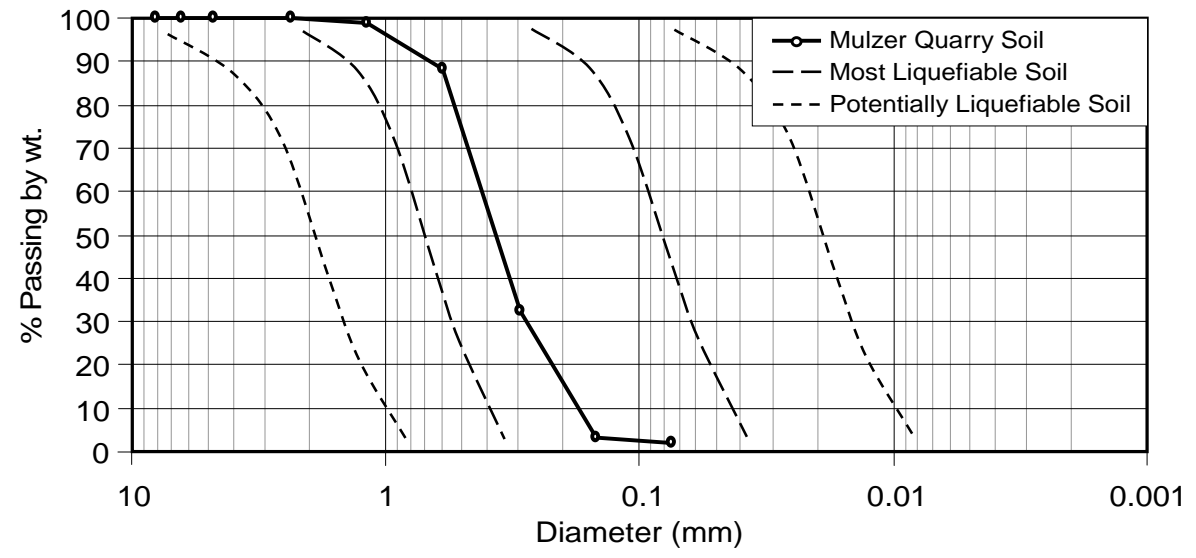

FIG. 2. Grain size distribution of sand from the loose sand layer. Superimposed on the plot are ranges of the grain size distributions of "Most Liquefiable Soil" and "Potentially Liquefiable Soil," per Tsuchida (1970).

\section{TYPES OF INSTRUMENTATION}

As stated above, the test site will be well instrumented with accelerometers, pore pressure transducers, and settlement tubes. The accelerometers will allow computation of both induced strains and energy dissipation in the liquefied soil. Pressure transducers will confirm the occurrence of liquefaction and will monitor dissipation of excess pore pressure with time and distance from the energy source. Finally, settlement tubes will provide settlement data as a function of depth and distance from the energy source. 


\section{Accelerometers}

The three methods that are being used to breakdown the soil structure impart seismic waves having very different amplitudes and frequencies. For example, blasting generates motions with amplitudes and frequencies three orders of magnitude greater than vibrocompaction and vibroseis. Consequently, different accelerometers are needed.

For blasting, piezoelectric shock accelerometers will be used because they can withstand the large amplitude motions generated from the explosion. Figure 3 shows data from Hryciw (1986) on the frequency and amplitude of blast pulses in saturated soils as a function of cube root scaled distance (i.e., distance divided by the cube root of charge weight). The frequency (f) of the peak acceleration was calculated by taking the inverse of four times the rise time $\left(t_{p}\right)$ (i.e., $\left.f=1 /\left(4 \times t_{p}\right)\right)$. In extrapolating to scaled distances less than $\sim 4 \mathrm{~m} / \mathrm{kg}^{1 / 3}\left(\sim 10 \mathrm{ft} / \mathrm{lb}^{1 / 3}\right)$, the authors applied factors of safety in estimating the peak accelerations and maximum frequencies to account for variations in field conditions. It was determined that the shock accelerometers must capture frequencies greater than $15 \mathrm{kHz}$ and peak amplitudes of 500,2500 , and $20,000 \mathrm{~g}$, depending on the scaled distance from the blast. Using these criteria, Dytran 3200 series shock accelerometers were selected for use. These accelerometers are sufficiently small in size ( $\sim 0.03 \mathrm{~m}$ with housing for placement in the ground) relative to the estimated wave length of the blast pulse $(\sim 0.15 \mathrm{~m}$ near charge, increasing to $\sim 0.5 \mathrm{~m}$ away from charge) that high frequencies should not be filtered.

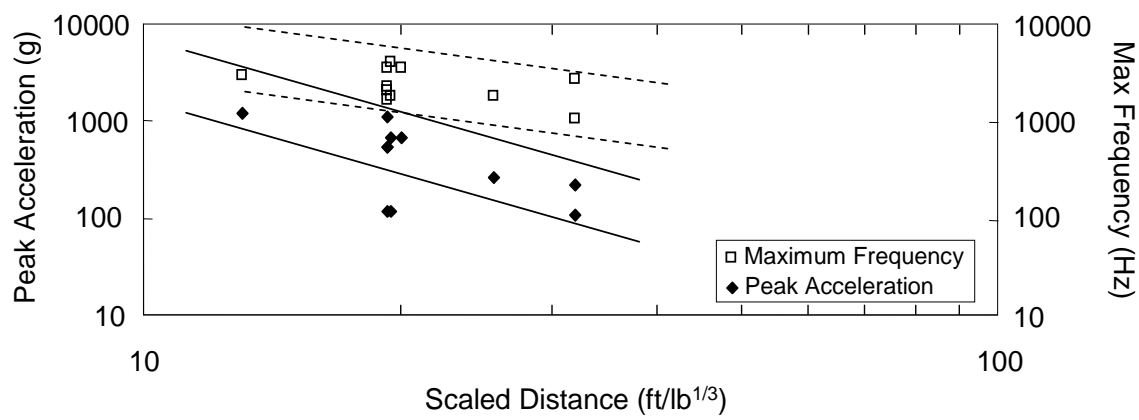

FIG. 3. Amplitude and frequency of blast pulse as a function of scaled distance from the explosive (adapted from Hryciw (1986)). $\left(1 \mathrm{ft} / \mathrm{lb}^{1 / 3} \approx 0.4 \mathrm{~m} / \mathrm{kg}^{1 / 3}\right)$.

Little information is available about the amplitude of ground motions generated during vibrocompaction. Using data for current vibrocompaction equipment and the methods described in Fellin (2000) and Green (2001), the authors calculated an upper bound for the maximum acceleration of the vibroflot as it impacts the soil. Clearly the maximum acceleration will attenuate with distance from the compaction point, but at an unknown rate. The authors chose triaxial Crossbow capacitive microelectromechanical systems (MEMS) accelerometers of 2, 5, 10, and 25g.

Extensive instrumentation experience exists for the vibroseis. The University of Texas NEES vibroseis "T-Rex" was used to liquefy a sand deposit at the Wildlife Liquefaction Site in California (Cox, 2006). Based on the data collected from that study, $2 \mathrm{~g}$ accelerometers will be used for the present study. 


\section{Pressure Transducers}

Previous studies of pore pressure generation and dissipation during blasting have identified instruments durable enough to survive the blast pulse, while sensitive enough to accurately record dissipation (Rollins et al., 2005). Sensotec P-050 piezoresistive transducers are capable of surviving an approximate $41.4 \mathrm{MPa}(6,000 \mathrm{psi})$ shock pressure wave while having a resolution of $0.7 \mathrm{kPa}(0.1 \mathrm{psi})$. These transducers are, therefore, responsive enough to define the pressure build up and dissipation. While vibrocompaction and vibroseis will not produce as high of a peak pore pressure as blasting, the instruments are sensitive enough to meet the project's needs. Because the bandwidth of the transducers is $0-300 \mathrm{~Hz}$, the peak pressure from the blast shock wave may not be accurately recorded; however, the instruments will accurately monitor residual pore pressure generation and dissipation.

\section{Settlement Tubes}

Finally, settlement tubes will record the soil profile's settlement as a function of depth, distance from the energy source, and time after the breakdown of the soil structure. Sondex settlement systems place metallic rings in a corrugated pipe that settles or heaves with the soil around it. A probe is passed through the piping that detects the location of the rings, allowing the user to measure both total settlement and incremental settlement with depth. This is particularly important for this project because the effects of aging can be directly compared with the amount or absence of settlement in a particular layer.

\section{DATA ACQUISITION}

As discussed in the following, both tethered and wireless data acquisition systems will be used to record data.

\section{Tethered Data Acquisition}

All data from the piezoelectric shock accelerometers and from the settlement tubes will be recorded using a tethered data acquisition system (DAQ). The accelerometers will connect to an Olson Instruments, Inc. Freedom Data PC. This DAQ uses a National Instruments $1.25 \mathrm{MS} / \mathrm{s}, 16$ channel PCI Data Acquisition Card to collect data. The authors have tested the Olson DAQ by sampling on 8 channels at $200 \mathrm{kHz}$ for 1 second. Based on the information presented in Figure 3, this sampling rate will accurately capture the blast pulse.

The Sondex settlement system is also cable-based, with the cable attached to the metal detecting probe. This system does not allow continuous monitoring of settlements. However, the authors will take settlement measurements at the same time as the CPT soundings are performed to allow correlations to be developed between increases in penetration resistance and settlement. 


\section{Wireless Data Acquisition}

In addition to the tethered DAQ discussed above, a wireless sensing network developed at the University of Michigan (Lynch et al., 2005) will be extensively used in the field study. Although wireless sensing networks have proven to be a great asset in geotechnical centrifuge testing (Wilson et al., 2007), they are just beginning to be used in geotechnical field testing and monitoring (e.g., Garich and Blackburn, 2007). Wireless DAQ offer several advantages over traditional tethered systems. First, cables running from the sensors in the ground to DAQ can be replaced with cables only from the sensors to the surface, where the wireless capabilities handle the transmission. This reduces the chances of cable damage and data corruption. Also, the wireless sensing network allows for a greater number of sensors to be used. For example, the project's blast tests are limited to 16 piezoelectric accelerometers due to the number of channels on the tethered DAQ. The wireless DAQ limits the number of sensors only in cases of high sampling rates for long duration. In such cases, data transmission must occur before the wireless sensing unit's random access memory (RAM) becomes full and begins to overwrite existing data with new data. However, in geotechnical engineering this is rarely a concern, and hence, the system has significant potential for geotechnical applications.

The wireless network that is being used in this field study is pictured in Figure 4 and is primarily built from commercial components. The network was originally developed for structural health monitoring and is capable of performing analog-to-digital conversion, data aggregation, data processing, and wireless transmission of raw and/or processed data to a receiving computer. With a sampling rate as high as $100 \mathrm{kHz}$, the wireless DAQ is capable of capturing all the data for this project, except for the blast accelerations. The analog-to-digital converter (ADC) has a resolution of 16-bits, matching the capabilities of most tethered DAQ. It is controlled by the unit's 8-bit Atmel Atmegal28 microcontroller, which has $128 \mathrm{kB}$ of read only memory (ROM) where different algorithms can be embedded for execution. Because the microcontroller has limited RAM, $128 \mathrm{kB}$ of off-chip RAM is included in the design of the unit's computational core allowing 64,000 data points to be stored on the wireless sensor at one time.

Cables from the MEMS accelerometers and the pressure transducers run from the depth of the liquefiable layer to the surface, where they connect with the wireless sensing unit. A $900 \mathrm{MHz}$ Maxstream 9Xcite wireless transceiver is being used to transmit the sensor data to a receiving laptop computer. The transceiver is integrated with the wireless sensing unit's architecture and is capable of communicating up to $300 \mathrm{~m}$ line-of-site with an over-the-air data rate of $38.4 \mathrm{Kbps}$. One laptop combined with the receiver from the wireless sensing unit will receive the data from all of the sensors deployed for testing during the vibrocompaction and vibroseis tests. 


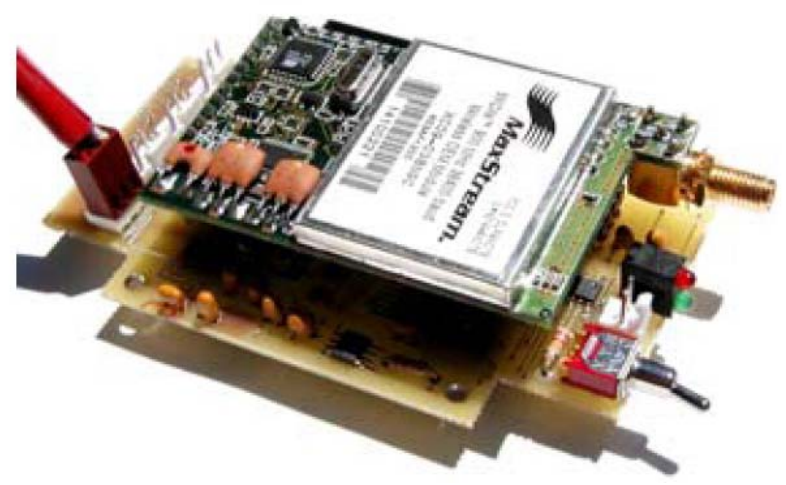

FIG. 4. Fully assembled wireless sensing unit prototype (battery and external housing not shown). When fully assembled the dimensions of the sensing unit are approximately $8 \times 15 \times 3 \mathrm{~cm}$.

\section{CONCLUSIONS}

Having appropriate instrumentation is absolutely essential to the success of the field portion of the NEESR sand aging study. During each test, a sensor array will capture the acceleration, pore pressure generation, and pore pressure dissipation in the liquefied layer. Additionally, settlement tubes will be used to monitor post-liquefaction settlement. Due to the varied amplitudes and frequencies of the motions being imparted to the soil by explosives, vibrocompaction, and vibroseis, each test requires a unique instrumentation plan to measure acceleration. Piezoelectric shock accelerometers will be used during blasting, while the vibrocompaction and vibroseis tests will use different combinations of MEMS accelerometers. Pore pressure transducers that are capable of both withstanding high-pressure shock waves and providing accurate readings at low-pressure levels will be used to monitor pore pressure in all of the tests. Settlement will be measured as a function of depth, distance from the energy source, and time after liquefaction using settlement tubes.

A tethered DAQ will record data from the piezoelectric accelerometers. All other instrumentation will utilize a wireless DAQ. By decreasing the chances of cable damage throughout testing and increasing the available sensor channels, the wireless DAQ greatly increases data acquisition capabilities.

\section{ACKNOWLEDGMENTS}

Support for the research presented herein came in part from the NSF NEESR grant CMMI 0530378. Mulzer Crushed Stone, Inc. donated the use of its quarry and the expertise of its employees. Dr. Richard Woods and Dr. Kyle Rollins provided valuable assistance in the selection of instrumentation. Mr. Jan Pantolin and Mr. Yongsub Jung provided valuable assistance characterizing the site. This support and assistance is gratefully acknowledged.

\section{REFERENCES}

Ashford, S.S., Rollins, K.M., and Lane, J.D. (2004). "Blast-Induced Liquefaction for 
Full-Scale Foundation Testing.” J. Geotechnical \& Geoenv. Engrg, Vol. 130(8): 798-806.

Charlie, W.A., Rwebyogo, M.F.J., and Doehring, D.O. (1992). "Time-Dependent Cone Penetration Resistance Due to Blasting." J. Geotechnical Engrg, Vol. 118(8): 1200-1215.

Cox, Brady (2006). "Development of a Direct Test Method for Dynamically Assessing the Liquefaction Resistance of Soils In Situ." Ph.D. dissertation, University of Texas, Austin, Texas.

Dowding, C.H. and Hryciw, R.D. (1986). "A Laboratory Study of Blast Densification of Saturated Sand.” J. Geotechnical Engrg, Vol. 112(2): 187-199.

Fellin, W. (2000). "Quality control in deep vibrocompaction." In Compaction of Soils Granulates and Powders, Advances in Geotechnical Engineering and Tunneling Vol. 3 (M. Kolymbas and W. Fellin, eds.). Balkema.

Garich, E.A. and Blackburn, J.T. (2007). "Automated, Wireless Instrumentation for Monitoring of Potential Landslide Hazards." Proc. $1^{\text {st }}$ American Landslide Conf., Vail, CO, June 3-8, 2007.

Green, R.A. (2001). "Energy-Based Evaluation and Remediation of Liquefiable Soils." $\mathrm{Ph} . D$. dissertation, Virginia Polytechnic Institute and State University, Blacksburgh, Virginia.

Hryciw, R.D. (1986). "A Study of the Physical and Chemical Aspects of Blast Densification of Sand." Ph.D. dissertation, Northwestern University, Evanston, Illinois.

Jamiolkowski, M., Ladd, C.C., Germain, J.T. and Lacellotta, R. (1985). "New Developments in Field and Laboratory Testing of Soils," Proc. $11^{\text {th }}$ Intern. Conf. on Soil Mechanics and Foundation Engineering, Vol. 1, San Francisco, 57-153.

Lynch, J.P., Wang, Y., Yi, J., Yun, C.B., Lu, K.C., and Loh, C.H. (2005). "Validation Case Studies of Wireless Monitoring Systems in Civil Structures." Proc. $2^{\text {nd }}$ Intern. Conf. on Structural Health Monitoring of Intelligent Infrastructure (SHMII-2), Shenzhen, China, November 16-18, 2005.

Mesri, G., Feng, T.W., and Benak, J.M. (1990). "Postdensification Penetration Resistance of Clean Sands." J. Geotechnical Engrg, Vol. 116(7): 1095-1115.

Mitchell, J.K. and Solymar, Z.V. (1984). "Time-Dependent Strength Gain in Freshly Deposited or Densified Sand.” J. Geotechnical Engrg, Vol. 110(11): 1559-1576.

Rollins, K.M., Lane, J.D., Dibb, E., Ashford, S.A., and Mullins, A.G. (2005). "Pore Pressure Measurement in Blast-Induced Liquefaction Experiments." Transportation Research Record: J. Transportation Research Board, Num. 1936, Transportation Research Board of the National Academies, Washington, 210-220.

Schmertmann, J.H. (1987). "Discussion of 'Time-Dependent Strength Gain in Freshly Deposited or Densified Sand,' by J.K. Mitchell and Z.V. Solymar.” J. Geotechnical Engrg, Vol. 113 (2): 173-175.

Tsuchida, H. (1970). "Prediction and Countermeasure against the Liquefaction in Sand Deposits." Abstract of the Seminar in the Port and Harbor Research Institute, 3.1-3.33 (in Japanese).

Wilson, D., Kutter, B., Ilankathara, M., and Robiadart, C. (2007). "The UC Davis High-Speed Wireless Data Acquisition System." Proc. Field Measurements in Geomechanics 2007, Boston, September 24-27, 2007. (In press) 